|| ISSN(online): 2589-8698 || ISSN(print): 2589-868X || International Journal of Medical and Biomedical Studies

Available Online at www.ijmbs.info

PubMed (National Library of Medicine ID: 101738825)

Index Copernicus Value 2018: 75.71

\title{
CLINICAL PROFILE OF NON-TRAUMATIC ACUTE ABDOMEN AT A TERTIARY CARE HOSPITAL- A RETROSPECTIVE STUDY.
}

\author{
Dr. Naveed Anjum Qureshi ${ }^{1}$, Dr. Viney Sambyal $*^{2}$ \\ ${ }^{1}$ Registrar Surgery, Post Graduate Department of Surgery, GMC Jammu. \\ ${ }^{2}$ Lecturer Medicine, Post Graduate Department of Medicine, GMC Jammu
}

Article Info: Received 23 March 2019; Accepted 15 April. 2019

Cite this article as: Qureshi, Dr. A., N., \& Sambyal, Dr. V. (2019). CLINICAL PROFILE OF NON-TRAUMATIC ACUTE ABDOMEN AT A TERTIARY CARE HOSPITAL- A RETROSPECTIVE STUDY. International Journal of Medical and Biomedical Studies, 3(4).

DOI: https://doi.org/10.32553/ijmbs.v3i4.203

Address for Correspondence: Dr. Viney Sambyal, Lecturer Medicine, Post Graduate Department of Medicine, GMC Jammu

Conflict of interest: No conflict of interest.

\section{Abstract}

BACKGROUND: Pain abdomen is a common presentation, it accounts for approximately $10 \%$ of the cases in emergency room and about $2-3 \%$ of the OPD patients.

METHODS: All non trauma patients presenting with pain abdomen to emergency, above the age of 15 years were included in the study. All diagnosed pregnant females were excluded from the study.

RESULTS: Most common cause of acute abdomen in our study was acute appendicitis followed by acute intestinal obstruction, cholecystitis and nephrolithiasis.

CONCLUSION: Clinicians must consider multiple diagnoses during workup of these patients, those patients who may require surgical exploration should be identified early to limit their morbidity and mortality.

\section{Introduction}

Abdominal pain is one of the most common emergencies presenting to emergency department (ED). It constitutes approximately $10 \%$ of the cases in the emergency department (1). It is a diagnostic challenge for the emergency physicians as the causes range from benign to life threatening conditions which may include Gastrointestinal, Urological, and Gynaecological among others (2). Although most abdominal pain is benign, as many as $10 \%$ of patients in the emergency department setting have a severe or life-threatening cause or may require surgery (3).Many diseases of which, some do not require surgical treatment produce abdominal pain, thus the evaluation of patient with acute abdominal pain must be methodical and careful (4). The elderly patients have atypical presentations with longer duration of pain at presentation (5). Most of the cases of acute abdomen can be diagnosed clinically by the presence or absence of abdominal pain, abdominal tenderness, guarding and rigidity whereas about a quarter of the patients usually remain with a non specific cause, but now with the latest radiological imaging that number has been reduced (6). Our study aims to determine the clinical profile and etiological spectrum of diseases presenting as acute abdomen at the emergency department. 


\section{Materials and Methods:}

This was a retrospective study conducted at the emergency department of Government Medical College, Jammu after obtaining approval from the Institutional ethics committee. It was conducted during the month of January 2014 to December 2015. All non trauma patients above 15 years of age presenting with abdominal pain to emergency department were included in the study. All diagnosed pregnant females were excluded from the study. After detailed history was taken and thorough clinical examination was done, $\quad X$ ray abdomen and Ultrasonography (USG) was done for all patients. Other radiological and blood investigations were done when required. Oral or parenteral analgesics were given according to severity of pain. The patients were followed up till discharge from ED/admitted ward and the final diagnosis at discharge was noted.

\section{Results}

A total of 410 patients were included in the study. Almost half 230 (56\%) of the patients were in the age group of $15-30$ years while 213 (30\%) patients were in the age group of $31-50$ years and only $14 \%$ were above 50 years of age (table 1). The minimum age of the patient in our study was 15 years and the maximum age was 82 years. The mean age was 32 years. $60 \%$ patients were male showing male predominance in our study (table 2). The onset of pain was sudden in $21 \%$ of patients whereas the pain was more than 3 days in duration in $79 \%$ of the patients (table 3). Comorbid conditions of diabetes mellitus, hypertension, ischemic heart disease, previous abdominal surgery, malignancy and tuberculosis were present in $06 \%, 05 \%, 0.8 \%, 4.5 \%, 2.8 \%$, and $01 \%$ of patients, respectively. (Table 4$)$.Common types of pain included dull aching (56\%), colicky (24\%), pricking $(10 \%)$, throbbing $(05 \%)$, and burning (05\%). 40\% patients reported lower abdominal pain, while $20 \%$ had upper abdominal location whereas the pain was generalized in $20 \%$ of patients. Common associated symptoms included nausea $(60 \%)$, vomiting $(40 \%)$, urinary symptoms $(17 \%)$, loss of appetite $(12 \%)$, constipation (10\%), diarrhoea $(9 \%)$, abdominal distension (3\%), and jaundice (03\%). Most common cause of acute abdomen in our study was acute appendicitis $25 \%$, followed by acute intestinal obstruction accounting for about $14 \%$ of the cases, nephrolithiasis and calcularcholecystitis were responsible in $13 \%$ and $12 \%$ cases respectively, pancreatitis in about $6 \%$ of the cases, acid peptic disease and perforated duodenal ulcer in $6 \%$ and $3 \%$ cases respectively, ruptured ectopic, acute myocardial infarction and mesenteric ischemia were among least common causes of acute abdomen in our study (Table 5). Out of total 410 patients $76 \%$ were admitted for further workup and management while $22 \%$ were discharged from emergency department while $02 \%$ of patients took discharge at request. 59 (14.33\%) patients developed complications of which metabolic acidosis and electrolyte disturbance were the two most common complications noted (Table $6)$. A mortality rate of $1.46 \%$ was noted in the study(Table 7).

TABLE 1: AGE DISTRIBUTION

\begin{tabular}{|c|c|c|}
\hline AGE(YRS) & NO OF PATIENTS & $\%$ \\
\hline $15-30$ & 230 & 56 \\
\hline $31-50$ & 123 & 30 \\
\hline$>50$ & 57 & 14 \\
\hline TOTAL & 410 & 100 \\
\hline
\end{tabular}

TABLE 2: SEX DISTRIBUTION

\begin{tabular}{|c|c|c|}
\hline SEX & NO OF PATIENTS & \% \\
\hline MALE & 246 & 60 \\
\hline FEMALE & 164 & 40 \\
\hline TOTAL & 410 & 100 \\
\hline
\end{tabular}

TABLE 3: DURATION OF PAIN

\begin{tabular}{|c|c|c|}
\hline SEX & NO OF PATIENTS & $\mathbf{\%}$ \\
\hline$<3$ & 325 & 79 \\
\hline$>3$ & 85 & 21 \\
\hline TOTAL & 410 & 100 \\
\hline
\end{tabular}

TABLE 4: COMORBIDITIES 


\begin{tabular}{|c|c|c|}
\hline COMORBIDITY & NO OF PATIENTS & $\%$ \\
\hline HYPERTENSION & 20 & 5 \\
\hline T2DM & 25 & 6 \\
\hline IHD & 3 & 0.8 \\
\hline $\begin{array}{c}\text { POST } \\
\text { LAPAROTOMY }\end{array}$ & 18 & 4.5 \\
\hline MALIGNANCY & 12 & 2.8 \\
\hline TUBERCULOSIS & 4 & 1 \\
\hline
\end{tabular}

TABLE 5: ETIOLOGY OF ACUTE ABDOMEN OF PATIENTS PRESENTING TO EMERGENCY.

\begin{tabular}{|l|l|l|}
\hline ETIOLOGY & $\begin{array}{l}\text { NO OF } \\
\text { PATIENTS }\end{array}$ & \% \\
\hline ACUTE APPENDICITIS & 102 & 25 \\
\hline ACUTE INTESTINAL OBSTRUCTION & 56 & 14 \\
\hline ACUTE ACALCULAR PANCREATITIS & 13 & 3.7 \\
\hline ACUTE CALCULAR PANCREATITIS & 14 & 3.14 \\
\hline ACUTE ACALCULAR CHOLECYSTITIS & 19 & 4.63 \\
\hline ACUTE CALCULAR CHOLECYSTITIS & 56 & 13.6 \\
\hline MESENTRIC ISCHEMIA & 3 & 0.73 \\
\hline PERFORATED PEPTIC ULCER & 15 & 3.65 \\
\hline PERITONITIS & 35 & 8.53 \\
\hline NEPHROLITHIASIS & 50 & 12.19 \\
\hline ECTOPIC PREGNANCY & 1 & 0.24 \\
\hline LIVER ABSCESS & 6 & 1.46 \\
\hline ACUTE MYOCARDIAL INFARCTION & 3 & 0.73 \\
\hline PLEURISY & 6 & 1.46 \\
\hline ACID PEPTIC DISEASE & 25 & 6.09 \\
\hline ACUTE RETENTION OF URINE & 6 & 1.46 \\
\hline TOTAL & 410 & 100 \\
\hline
\end{tabular}

TABLE 6: COMPLICATIONS AMONG PATIENTS

\begin{tabular}{|l|l|l|}
\hline COMPLICATIONS & NO OF PATIENTS & $\%$ \\
\hline $\begin{array}{l}\text { ACUTE RENAL } \\
\text { FAILURE }\end{array}$ & 12 & 2.9 \\
\hline SHOCK & 5 & 1.2 \\
\hline $\begin{array}{l}\text { METABOLIC } \\
\text { ACIDOSIS }\end{array}$ & 25 & 6.09 \\
\hline $\begin{array}{l}\text { ELECTROLYTE } \\
\text { IMBALANCE }\end{array}$ & 16 & 3.9 \\
\hline GI & 1 & 0.24 \\
\hline TOTAL & 59 & 14.33 \\
\hline
\end{tabular}

TABLE 6: MORTALITY AMONG PATIENTS

\begin{tabular}{|l|l|l|}
\hline & NO OF PATIENTS & $\%$ \\
\hline SURVIVORS & 404 & 98.53 \\
\hline NONSURVIVORS & 6 & 1.46 \\
\hline TOTAL & 410 & 100 \\
\hline
\end{tabular}

\section{Discussion}

Immediate Acute abdomen may be defined as "An abnormal condition characterised by sudden onset of severe pain within the abdominal cavity which requires immediate evaluation, diagnosis and may require surgical intervention". (7) All patients with abdominal pain do not require extensive diagnostic tests. Sometimes, adequate history and physical evaluation alone is sufficient to accurately diagnose the condition and treat accordingly. Patients may present with vague complaints and varying associated symptoms making diagnosis difficult which ranges from benign to life threatening conditions. (2)More than half of them reported their pain as sudden onset while the remainder described their pain as gradual in onset. In our study, the most common site of radiation of pain was and was reported by $10 \%$ of our patients. This correlates with the large number of ureteric colic patients $(12 \%)$ in our study. Though many other associated symptoms were recorded, their value in establishing a firm diagnosis could not be established. Medical literature also suggests that associated symptoms often lack specificity and atypical presentations are common. $[6,8]$ Causes of acute abdominal pain include both medical and surgical. [8] In an observational study by Tariq et al. from Pakistan the most common cause of acute abdomen was acute appendicitis followed by acute pancreatitis and duodenal ulcer [9] which partially correlates with our study. A study done in Ghana, Africa, also reported acute appendicitis followed by typhoid fever with ileal perforation and acute intestinal obstruction as most common causes of acute abdominal pain.(10)

The modern physician should be humbled by the fact that, despite diagnostic and therapeutic advances (computed tomography [CT], ultrasonography, and laparoscopy), the 
misdiagnosis rate of the most common surgical emergency, acute appendicitis, has changed little over time.(11)

\section{Conclusion}

Acute abdomen is a common ailment in the emergency room and many intraabdominal conditions share nonspecific symptoms. Apart from relieving the patient's symptoms, the emergency physician's primary role is to identify those cases that require immediate intervention in order to limit morbidity and mortality. Inspite of thorough history, clinical examination, laboratory and radiological investigations diagnosis remains elusive in a small subset of these patients. An unexpected negative test result should prompt a reassessment of the patient. Serial examination and identification of patients who may require urgent exploration is a sound strategy.

\section{References}

1. Lameris $W$, van Randen $A$, van Es HW, van Heesewijk JP, van Ramshorst B, Bouma WH, et al: Imaging strategies for detection of urgent conditions in patients with acute abdominal pain: diagnostic accuracy study. BMJ 2009;338:b2431.

2. Agboola JO, Olatoke SA, Rahman GA. Pattern and Presentation of Acute Abdomen in a Nigerian Teaching Hospital. Niger Med J. 2014;55:266-70. [PMCID: PMC4089059] [PubMed: 25013262]

3. Kamin RA, Nowicki TA, Courtney DS, Powers RD. Pearls and Pitfalls in the Emergency Department Evaluation of Abdominal Pain.
Emerg Med Clin North Am. 2003;21:61-72. [PubMed: 12630731]

4. Town send CM. Sabiston textbook of Surgery: The biological basis of modern surgical practice 16 Ed. Singapore: Harcourt Asia PTE Ltd., W. B. Saunders Co., 2001.

5. Laurell $H$, Hansson LE, Gunnarsson U. Acute Abdominal Pain among Elderly Patients. Gerontology. 2006;52:339-44. [PubMed: 16905885]

6. Powers RD, Guertler AT. Abdominal Pain in the ED: Stability and Change over 20 Years. Am J Emerg Med. 1995;13:301-3. [PubMed: 7755822]

7. Mosby's dictionary of Medicine, Nursing and Health Professionals. 7th ed. Missouri: Mosby Elsevier Inc; 2006. p. 30.

8. Saleh MA, Troy S, Etienne T. What Clinical and Laboratory Parameters Determine Significant intraabdominal Pathology for Patients Assessed in Hospital with Acute Abdominal Pain? World J Emerg Surg. 2007;2:26. [PMCID: PMC2116997] [PubMed: 17894892]

9. Muhammad TA, Asma H, Waqar SH, Shah SF, Zafar IM, Zahid MA. Presentation and Outcome of Acute Abdomen in a Tertiary Care Unit. Ann Pak Inst Med Sci. 2011;7:137-44. 10.

10. OheneYeboah M. Acute surgical admissions for abdominal pain in adults in Kumasi, Ghana. ANZ J Surg. 2006;76:898-903. [PubMed: 17007619]

11. Flum DR, Morris A, Koepsell $T$, et al. Has misdiagnosis of appendicitis decreased over time? JAMA.2001;286:1748-1753. [PubMed] 